\title{
ANÁLISE DAS RELAÇÕES DE TRABLHO À LUZ DO PROCESSO DE INCUBAÇÃO DA CANTINA DO MÓDULO UM DA UNIVERSIDADE ESTADUAL DE FEIRA DE SANTANA
}

\author{
Maria Luiza Souza Mendes de Araújo;
}

1. Bolsista PIBIC/CNPq, Graduando Direito, Universidade Estadual de Feira de Santana, e-mail: marialuizasma@ gmail.com 2. Orientador, DCIS, Universidade Estadual de Feira de Santana, e-mail: fa-pita@bol.com.br

PALAVRAS-CHAVE: Economia Solidária. Relação de trabalho. Cooperativa.

\section{INTRODUÇÃO}

Diante da conjuntura econômica e social brasileira, a economia popular e solidária pode ser tratada como uma saída plausível para as pessoas que acabam sofrendo os efeitos com a crise no modo de produção capitalista, principalmente com o quadro de demissão que assolam diversas empresas.

Conforme este entendimento busca-se estudar as relações de trabalho que se constrói dentro desta nova forma de se organizar, para se perceber qual a carga e dificuldade trazida pelos grupos que passaram por outras experiências que dificultam ou facilitam a adaptação deles a esta nova organização.

Acontece que a organização popular e solidária de um grupo mexe muito com a ideia de hierarquia que o sistema capitalista impõe como necessário para a concepção de qualquer estrutura de gestão. Por isso, o artigo tem como tema a relação de trabalho construída em um grupo de economia popular e solidária no início do processo de incubação, e suas peculiaridades para não configurar uma forma de burlar as leis e garantias trabalhistas.

O objetivo deste trabalho é observar a carga de experiência que o grupo possui no início do processo de incubação, dificultado o trabalho no modo de produção da economia popular e solidária no que se refere à construção das relações trabalhistas entre os membros do grupo, principalmente no que diz respeito às desconstruções da ideia de hierarquia e construção de uma gestão igualitária do grupo.

As cooperativas de Trabalho estão regulamentadas principalmente pela Lei $n^{\circ} 12.690$ de 19 de julho de $2012^{1}$, que traz conceitos que norteiam os estudos no que se refere às construções de relações trabalhistas dentro deste tipo de grupo, principalmente no que tange o Art. $2^{\circ}$ desta Lei:

"Art. $2^{\underline{0}}$ Considera-se Cooperativa de Trabalho a sociedade constituída por trabalhadores para o exercício de suas atividades laborativas ou profissionais com proveito comum, autonomia e autogestão para obterem melhor qualificação, renda, situação socioeconômica e condições gerais de trabalho. $\S 1^{\circ}$ A autonomia de que trata o caput deste artigo deve ser exercida de forma coletiva e coordenada, mediante a fixação, em Assembleia Geral, das regras de funcionamento da cooperativa e da forma de execução dos trabalhos, nos termos desta Lei."

O entendimento trazido por este artigo é que as relações de trabalho neste tipo de grupo se edifica através de uma autonomia coletiva e coordenada, tendo papel fundamental a Assembleia Geral. O que se toca neste ponto é a hierarquia, que é bastante modificada nos grupos, pois os agentes dos grupos tem uma maior igualdade entre eles.

\footnotetext{
${ }^{1}$ BRASIL. Lei no 12.690 , de 19 de julho de 2012. Dispõe sobre a organização e o funcionamento das Cooperativas de Trabalho; institui o Programa Nacional de Fomento às Cooperativas de Trabalho PRONACOOP; e revoga o parágrafo único do art. 442 da Consolidação das Leis do Trabalho - CLT, aprovada pelo Decreto-Lei $n^{\circ} 5.452$, de $1^{\circ}$ de maio de 1943.
} 
Além da noção de cooperativa, é importante mencionar que aos conceitos trazidos pela lei são acrescentados os ideais da economia solidária, com isso, os conceitos do grupo são compatíveis com o que é pensado sobre esse modo de produção por Paul Singer²:

"A economia solidária é outro modo de produção, cujos princípios básicos são a propriedade coletiva ou associação do capital e o direito à liberdade individual. A aplicação desses princípios une todos os que produzem numa única classe de trabalhadores que são possuidores de capital por igual em cada cooperativa ou sociedade econômica. [...] (SINGER, Paul, 2002, pg.10)".

No que concerne as relações de trabalho, a construção deve ser sempre de igualdade dentro do grupo, também no que envolve a autogestão e a forma de dividir os ganhos.

Essas espécies de requisitos são fundamentais para que um grupo realmente trabalhe no sistema de Economia Solidária.

A luz desses fatores que se observou o início do processo de incubação do Grupo Sabores, para identificar os comportamentos e formas de gestão que se mostraram mais difíceis para se moldar a esse modo de produção.

Um agravante sofrido por este grupo foi a experiência que eles já tinham dentro dos moldes capitalistas. Acontece que quem já se familiarizou com as formas de produzir do capitalismo, pode usar o cooperativismo de economia solidária para burlar os direitos trabalhistas de quem faz parte do grupo, principalmente os que foram convidados ou entraram depois da sua criação.

\section{MATERIAL E MÉTODOS OU METODOLOGIA (ou equivalente)}

A metodologia utilizada foi um estudo doutrinário sobre o tema, pra esclarecer este modo de produção e como se dá a organização das relações de trabalho. Tocando neste ponto, utilizou-se de uma análise da lei de cooperativas, bem como de outras leis que tratem do tema, para que se possa entender como o ordenamento jurídico brasileiro trata dos direitos trabalhistas daqueles que se inserem neste modo de produção diferenciado, bem como os critérios que um grupo deste tipo deve seguir para gozar dos benefícios de uma cooperativa e não configurar apenas uma forma de driblar as leis trabalhistas.

Por fim, foi aplicado um questionário no qual os membros do grupo respondiam perguntas que versavam sobre como se sentiam inseridos no grupo, como ocorriam as divisões dos trabalhos e como eles achavam que elas deveriam acontecer, além de se questionar se eles enxergavam alguma hierarquia dentro do grupo.

Além dos questionários foram feitas dinâmicas com o grupo recém-incubado para conhecê-los melhor, o que trouxe uma visão bastante real das relações e estruturas criadas entre eles, coisas que as entrevistas não podiam mostrar.

\section{RESULTADOS E/OU DISCUSSÃO (ou Análise e discussão dos resultados)}

A discussão analisou os requisitos para a formação da relação de emprego para comparar com a relação criada dentro da lógica da economia solidária, expondo o que é necessário para demonstrar a subordinação, a alteridade, habitualidade, onerosidade, pessoalidade, de modo a demonstrar que, os três últimos citados são comuns aos dois tipos em questão, além de discutir como foi identificado a presença dos dois primeiros para desqualificar a relação solidária que se tentava construir.

Para isso, três perguntas se mostraram mais esclarecedoras para a problemática:

\footnotetext{
2 SINGER, Paul. Introdução à economia solidária. São Paulo: Perseu Abramo, 2002.
} 
"Como foi a escolha do nome do Grupo?"

\begin{tabular}{|c|c|c|}
\hline "Líder" escolheu & Não Sabe / já existia & $\begin{array}{c}\text { "Líder" escolheu e } \\
\text { consultou grupo }\end{array}$ \\
\hline 3 & 3 & 3 \\
\hline
\end{tabular}

Como se pode notar, de acordo com as respostas proferidos pelos integrantes do grupo, todos eles demonstraram uma estrutura hierárquica com determinações que segue de cima pra baixo, quebrando os ideais de autogestão.

A segunda pergunta escolhida foi: "Como vocês têm decidido sobre o modo de realizar o trabalho?". Essa pergunta foi feita para entender como foi escolhido o modo de divisão das tarefas da cantina, de modo a verificar a democratização nas escolhas dos trabalhos enquanto demonstração de importante requisito da autogestão. Como resultado obtido, demostra-se a tabela abaixo:

\begin{tabular}{|c|c|c|c|}
\hline Segue ordens & Conjunto/Reuniões & Por perfil/atividades & $\begin{array}{c}\text { Proposição do grupo } \\
\text { aprovada pela } \\
\text { "Líder" }\end{array}$ \\
\hline 2 & 4 & 2 & 1 \\
\hline
\end{tabular}

Sobre essa última categoria de resposta, muito se assemelha a forma de construir as decisões em grupos com grande número de integrantes, que apresentam a necessidade de um líder legitimo para coordenar os atos do grupo. Acontece que, nesses casos, não há a aprovação de qualquer decisão por esse líder, a decisão e as necessidades são demostrada pelo grupo e o líder apenas executa as coisas como foram acordadas democraticamente.

A terceira pergunta escolhida foi: "Como foi combinada a forma de divisão do dinheiro obtido com o trabalho?":

\begin{tabular}{|c|c|c|c|}
\hline Reuniões & $\begin{array}{c}\text { Pagar as } \\
\text { despesas e dividir } \\
\text { o resto }\end{array}$ & Salário & $\begin{array}{c}\text { Criação de plano } \\
\text { pra ver quem } \\
\text { concorda }\end{array}$ \\
\hline 2 & 3 & 1 & 1 \\
\hline
\end{tabular}

As respostas nessa pergunta se mostraram vagas. Quando resumidas apenas em "reuniões", aparentava evitar explicar em detalhes. Uma divisão igualitária depois de pagas as despesas seria o ideal se não surgisse uma resposta tão contraditória como a do pagamento de salário, criando um tratamento totalmente desigual entre os participantes do grupo.

\section{CONSIDERAÇÕES FINAIS (ou Conclusão)}

Para entender melhor a entrevista e as conclusões alcançadas por este artigo é importante considerar que foi tratada como "Líder" uma pessoa que se destacou nas tomadas de decisões referentes à gestão da Cantina, como se que estava hierarquicamente superior aos demais integrantes do grupo. É imprescindível acrescentar que a forma como foi empregada o termo Líder não guarda nenhuma relação com a figura dos líderes de grupos de economia popular e solidária, a qual se montra uma figura democrática, que apenas gerencia as necessidades do grupo, que são elencadas democraticamente, sem construir uma hierarquia.

Sendo assim, quando tratamos da Líder no corpo do trabalho podemos observar que essa figura mostrou-se como superior hierárquico. Desde o momento de formação do grupo, ao convidar muitos dos membros o grupo já tinha nome e estrutura, ou quando estes não participaram do seu processo de criação, reforçou-se a situação demostrada. 
Nesse grupo em questão, havia um agravante, pois muitos dos seus integrantes já formavam uma estrutura capitalista que trabalhava em outro espaço da cidade. Separar os espaços e suas formas de se relacionar não é uma tarefa fácil, sendo assim, conclui-se que, apesar de ser importante os componentes já terem tido experiências em empresas capitalistas, é difícil alcançar o sucesso ao exercer atividades nos dois modos de produção simultaneamente.

Outro ponto que dificulta a formação de relações igualitárias é o fato de o capital do grupo no momento de sua formação, pertencer a um componente ou parte do grupo. Isso porque quando o investimento é concentrado, abre-se margem para que aquele que investiu queira ser compensado financeiramente com aquilo que foi fruto do trabalho de todos. É importante mencionar que as estratégias capitalistas ficam marcadas nas atitudes comerciais daqueles que sempre conviveram e se relacionaram em uma sociedade em que é dominante esse modo de produção. Então, se torna natural o fato de aquele que investiu em um negócio, mesmo que fosse para o bem de uma coletividade, querer tirar vantagem do capital que imobilizou para aquilo.

Esse investimento abre o precedente de a contrapartida dada ao investimento feito por um ou parte do grupo ser feita através da exploração da mão-de-obra dos demais. Com isso, se constrói novamente um padrão capitalista de criar relações de trabalho e produção.

Portanto, o que se tornou imprescindível para que o grupo conseguisse criar relações igualitárias, em primeiro lugar, seria um investimento igual por parte de todos os componentes do grupo, para que todos se sentissem "donos" da mesma parcela dos bens de capital necessários para realização da atividade. Depois, é muito importante que os membros não componham, fora do grupo, uma relação hierarquizada, para que isso não crie um sentimento de limitação da liberdade do poder de escolha de cada membro, ou que faça parecer que alguns tenham opiniões mais relevantes que outros.

\section{REFERÊNCIAS}

BRASIL. Lei $\mathrm{n}^{\circ} 12.690$, de 19 de julho de 2012. Dispõe sobre a organização e o funcionamento das Cooperativas de Trabalho; institui o Programa Nacional de Fomento às Cooperativas de Trabalho - PRONACOOP; e revoga o parágrafo único do art. 442 da Consolidação das Leis do Trabalho - CLT, aprovada pelo Decreto-Lei $n^{\circ} 5.452$, de $1^{\circ}$ de maio de 1943. Visto no site http://www.planalto.gov.br/ccivil_03/_Ato20112014/2012/Lei/L12690.htm, acesso em 04 de dezembro de 2015.

SINGER, Paul. Introdução à economia solidária. São Paulo: Perseu Abramo, 2002.

CUNHA, Gustavo Brito da. A utilização inadequada das cooperativas de trabalho no processo de terceirização. Revista Fórum trabalhista: RFT, Belo Horizonte, v. 2, n. 6, p. 4374, mai./jun. 2013.

NELSON, Rocco Antonio Rangel Rosso. Das cooperativas de trabalho: instrumento usado na dissimulação da relação de emprego e consequente alijamento dos direitos sociais. Revista de Direito do Trabalho, São Paulo, v. 39, n. 153, p. 73-90, set./out. 2013.

MRTINS, Sérgio Pinto. Direito do Trabalho. 30 Edição, São Paulo, Editora Atlas, 2014.

OLIVEIRA, Benedito Anselmo Martins de. O Capital Social nas Cooperativas Populares e suas Relações com a Economia Solidária. Março de 2005. 